Recibido: 20 de marzo de 2009

Aprobado: 25 de mayo de 2009

\title{
ÉTICA Y DETRASCENDENTALIZACIÓN EN JÜRGEN HABERMAS ${ }^{1}$
}

\section{ETHICS AND DETRACENDENTALIZATION ON JÜRGEN HABERMAS}

\author{
Leonardo Tovar González ${ }^{2}$
}

\section{Resumen}

El texto se centra en el proceso de detrascendentalización de la filosofía moral de Habermas, que de la ética discursiva entendida como traducción comunicativa de la fundamentación a priori de la moralidad en Kant, ha evolucionado hacia una especie de cognitivismo prágmático, que vincula los principios morales con la praxis histórica. En este marco, el criterio de corrección moral ya no reside primariamente en la aceptabilidad consensuada de las normas y acciones a través de acuerdos alcanzados por medios argumentativos, sino en la capacidad de los consensos vigentes para ampliarse con el fin de incluir a las personas y grupos sociales injustamente excluidos.

\section{Palabras clave}

Cognitivismo, ética discursiva, pragmatismo, razón comunicativa.

\begin{abstract}
The text has got its centre into the process of detracendentalization of moral philosophy of Habermas that from the discursive ethics understood as a communicative translation of the a-priori basis of morality present on Kant has evolved to specie of pragmatic cognitivism that joins the moral principles and the historical praxis. Under this framework, the criteria
\end{abstract}

1 Bogotá, noviembre de 2008. La versión original de este documento procede del segundo semestre de 2006, en el marco del seminario sobre "Ética discursiva y política deliberativa en Jürgen Habermas", orientado por Guillermo Hoyos y Ángela Calvo en la Universidad Javeriana.

2 Universidad Santo Tomás. Aspirante al DIE- Doctorado Inter-Institucional en Educación de la Universidad Pedagógica Nacional, la Universidad Distrital y la Universidad del Valle, en el énfasis "Filosofía y enseñanza de la filosofía". 
of moral correction does not reside already primarily on the minded acceptability of the actions and rules trough out the arrangements reached by argumentative media, but into the capacity of the actual consensus to amplify itself, with propose of including people and social groups unfairly excluded.

\section{Key words}

Cognitivism, discursive ethics, pragmatism, communicative reason.

¿Los enunciados morales son mera expresión de sentimientos, preferencias, convenciones sociales o intuiciones inefables? O por el contrario, ¿poseen un valor cognitivo? $\mathrm{Si}$ optamos por la segunda alternativa, ¿en qué consiste la validez cognitiva de los enunciados morales? ¿Cuáles son las semejanzas y diferencias entre los criterios de validez cognitiva de los discursos morales y los criterios de validez cognitiva de los discursos empíricos?, y sobre todo, ¿cuáles son las implicaciones prácticas del estatuto cognitivo de los enunciados morales? Es decir, ¿qué relación existe entre su estatuto cognitivo y su poder moral vinculante como orientación de la práctica humana?

Contra interpretaciones emotivistas, convencionalistas o intuicionistas de lo moral, Jürgen Habermas se ha ubicado de modo decidido en el actual debate metaético dentro de la vertiente que sostiene la susceptibilidad de evaluación gnoseológica de la moralidad, según principios que nos permiten optar racionalmente entre dos o más enunciados alternativos (criterio de selección) o establecer la evolución del juicio moral (criterio de progreso). Sin embargo, a diferencia de Karl-Otto Apel, quien ha perseverado en una fundamentación comunicativo-trascendental de la ética discursiva, la versión habermasiana ha evolucionado desde un cognitivismo discursivo hacia un cognitivismo pragmático.
En su proyecto de transformación discursiva de la ética Kantiana, Apel ha sustituido el "yo pienso" que sirve de supuesto del principio de universalización recogido en el imperativo categórico, por el "nosotros argumentamos" inherente a la capacidad comunicativa que performa el lenguaje. De esta manera, la corrección moral ya no se remite a una conciencia solitaria que elige su curso de actuación según criterios de consistencia lógica alcanzados mediante la reflexión meramente subjetiva, sino a través del ejercicio intersubjetivo de la argumentación en una comunidad de hablantes que dialoga en procura del acuerdo normativo sobre los valores y prácticas en juego. No obstante, para evitar el decisionismo arbitrario en que terminan coincidiendo neopositivistas, racionalistas críticos y existencialistas, así como el relativismo y el escepticismo contextualistas de comunitaristas, pragmatistas, hermeneutas, posmodernos e incluso neo-marxistas, Apel estima imprescindible conservar el kantiano estatuto trascendental en el transformado marco comunicativo de la ética. El a priori discursivo se erige como el nuevo principio trascendental de la razón práctica, ya que la capacidad comunicativa del lenguaje constituye la condición irrebasable que no pueden cuestionar sensatamente los irracionalistas, sin incurrir en contradicción performativa. De allí que deba suponerse la acción regulativa de una hipotética "comunidad ideal de comunicación", encargada de orientar 
contrafácticamente los diálogos efectivos adelantados por las comunidades históricas.

Contra los consabidos riesgos de una ética de la intención a ultranza incapaz de intervenir con realismo en el curso del mundo, Apel ha incluido un principio de responsabilidad histórica que incorpora consideraciones prudenciales en la puesta en práctica de los criterios deontológicos derivados del a priori argumentativo. Precisamente, en tanto participantes de la comunicación, los agentes morales no pueden ser ciegos a las circunstancias ni a las consecuencias de la aplicación de las normas, y por ello deben oponer al kantiano fiat iustitica, pereat mundus ("hágase lo justo, aunque se destruya el mundo"), el primado de la conservación de la comunidad histórica de hablantes, pues a falta de esta desaparecería la posibilidad de alcanzar las condiciones de la comunidad ideal de habla. En contrapartida, nunca debe olvidarse que esta última se postula como supuesto trascendental normativo que sirve de instancia última para juzgar los diálogos históricos y orientar contrafácticamente las actuaciones reales. Para formularlo sintéticamente, el principio de responsabilidad apunta en últimas al cumplimiento histórico del principio discursivo.

También en la línea trazada por Kant, Habermas no entiende los principios éticos como una extensión naturalista de los criterios evaluativos del conocimiento empírico, sino según una comprensión analógica que distingue categorialmente entre las condiciones de "mero saber" del "ser" y las condiciones de "saber y deber" del "deber ser". Contra los escépticos, se reivindica que "es una y la misma razón la que tiene un uso teórico y un uso práctico", pero en prevención de la falacia naturalista y la confusión de la vigencia social de una prescripción con su corrección normativa, precisamente debe diferenciarse entre estos dos usos.
Desde luego, en Habermas la distinción ya no se ejercerá sobre la razón monológica fundada por Descartes, estructurada por Kant y agotada por Husserl, sino respecto de la racionalidad intersubjetiva mediada por el lenguaje.

En el marco fenomenológico discursivo de la "Teoría de la acción comunicativa" (Habermas, 1981, pp. 122 y ss.) la relación se establece a través de conceptos diferenciados de mundo. En las proposiciones propias del conocimiento teórico, se presupone un mundo objetivo, entendido como el conjunto de "lo que es el caso", que sirve de referencia a un saber verdadero o de objetivo de una intervención eficaz. Los enunciados prácticos requieren también de postular un mundo objetivo, ya que implican presuposiciones existenciales que los posibilitan, pero para su definición exigen agregar la relación con un "mundo social", definido como el conjunto de regulaciones legítimas de las interacciones humanas.

La comunicación argumentativa opera en ambos dominios como procedimiento de validación, pero con distinciones en las respectivas aplicaciones. En el primer caso, Habermas postula un modelo consensual de verdad, en el cual el consenso idealizado de la comunidad epistemológica de hablantes, define "lo que es el caso". Por supuesto, no se trata de un acuerdo arbitrario, pero serán las buenas razones concertadas dialógicamente las que constituyan la referencia del mundo objetivo (Habermas, 1972, pp. 113-160), y no a la inversa como sucede en Kant, donde la coincidencia de criterios subjetivos sólo sirve de indicio de la objetividad de la referencia sobre el mundo objetivo. A su turno, la corrección moral se define según el principio discursivo de universalización, en virtud del cual sólo son válidas las pretensiones normativas cuyas consecuencias sean susceptibles de aprobación efectiva de todos los posibles afectados, como participantes de procesos 
dialógicos marcados por los mejores argumentos (Habermas, 1983, p. 117). En ambos casos, el consenso a través del lenguaje sirve de telos discursivo que define asintóticamente la verdad teórica y la corrección práctica.

Dentro del proceso de "detrascendentalización" emprendido por Habermas en los noventa, el lenguaje se ha "degradado", ciertamente no en el sentido "fuerte" adherido al argot militar, pero sí en la acepción "débil" evocada cuando hablamos de la "degradación" de un color. En el campo teórico, se distingue más cuidadosamente entre condiciones de sentido, relativas a la validación intersubjetiva de una hipótesis cognitiva, y las condiciones de referencia, vinculadas a la correspondencia con un mundo objetivo común que "se resiste" a nuestras pretensiones cognitivas o técnicas. Como demuestran los innovadores en la ciencia, podría suceder que el consenso científico en un momento dado, fuera "falsado" con respecto al efectivo estado de cosas.

En "Acción comunicativa y razón sin trascendencia" (como fue vertido al español con cierto equívoco el título de su escrito en homenaje a Thomas Mc Carthy, que en alemán se denomina literalmente "Acción comunicativa y razón detrascendentalizada”), documento dedicado a tender puentes con la filosofía analítica más reciente, Habermas identifica su nueva posición epistemológica como un "realismo interno" (pp. 26 y ss), en el sentido de Putnam, que distingue entre la realidad como conjunto de los estados de cosas susceptibles de enunciación en el lenguaje, y el mundo objetivo como la totalidad de los objetos cuya existencia "se resiste" a nuestra capacidad de representación en el lenguaje. En los límites de la realidad así definida, podemos entender la verdad como "asertabilidad idealmente justificada", mientras el mundo se abre como orientación que regula en términos de aceptabilidad racional nuestro acceso a los objetos.
Análogamente, en los convenios argumentativos de carácter moral, también aparece ahora una resistencia extrínseca al lenguaje, pero esta no procederá del mundo objetivo sino de los sectores marginados de los compromisos discursivos históricos. Aunque las presuposiciones existenciales siguen gravitando sobre las pretensiones prácticas, será la protesta de los actores que denuncian su exclusión de los convenios normativos y exigen su inclusión en los bienes derivados de aquellos, la que servirá ahora de principio objetivo de corrección moral.

La transformación habermasiana en los respectivos estatutos de la verdad teórica y la justificación práctica resulta evidente, si bien se preserva el esquema analógico que permite interpretar cognitivistamente la moral. En los trabajos de los ochenta, el mundo de la vida estructurado comunicativamente, se concebía como a priori indiscutible sobre el cual se edificaban discursivamente a través de argumentos teóricos o morales, según el caso, la verdad de las proposiciones teóricas o la corrección de las prescripciones prácticas. En los noventa y la primera década del nuevo siglo, el mundo de la vida se comprende como escenario histórico de las acciones humanas, donde la comunicación efectiva sirve de mediación para resolver los problemas derivados de las aspiraciones de un saber verdadero y una intervención eficaz sobre el mundo objetivo, de un lado, y del otro, de la justificación de un obrar correcto y de unos valores legítimos con respecto al mundo práctico.

La correspondencia se preserva porque el lenguaje sigue constituyéndose en procedimiento de validación, pero se lo aligera de las cargas de "falsación" cognitiva y de "revisión" normativa, que se trasladan ahora a la referencia a un mundo objetivo y a la "lucha por la inclusión" en el mundo práctico. En el justo medio entre el trascendentalismo discursivo de Apel y el contex- 
tualismo pragmatista de Rorty, en esta etapa Habermas no define la comunicación a partir de condiciones idealizadas ni la disuelve en los intercambios de sentimientos de las conversaciones efectivas, sino la entiende como estructura inmanente que sólo se actualiza en los diálogos históricos en el mundo de la vida. En Acción comunicativa y razón sin trascendencia, nuestro autor habla de una "trascendentalidad desde dentro", con el fin de indicar que las presuposiciones del acuerdo posible en los saberes problematizados y en los acuerdos normativos denunciados, son asumidas performativamente por el participante en una acción o enunciación resolubles en el lenguaje, sin que ello implique ninguna remembranza kantiana o apeliana a condiciones a priori distinguibles de las prácticas históricas efectivas del lenguaje. Aunque la argumentación intersubjetiva sigue operando como canal de resolución de las pretensiones disputadas en los desacuerdos teóricos y los conflictos valorativos, son la correspondencia empírica y las reivindicaciones prácticas efectivas, las que fijan los contenidos de las respuestas. Expresado en términos lógicos, el lenguaje ya no es condición suficiente de verdad y corrección, pero persiste como condición necesaria de validez teórica y justificación práctica. Al fin de cuentas, los otros expresan sus objeciones teóricas y sus críticas normativas mediante discursos.

Ahora bien, el giro pragmatista no significa que se debiliten los requisitos racionales del saber ni de la acción. De una parte, el éxito explicativo de las hipótesis teóricas determinará su vigencia epistemológica. De otra, la capacidad de inclusión universal de todos los afectados y potencialmente de toda la humanidad, marca la legitimidad de los discursos normativos. Más aún, en esta última esfera de lo moral, Habermas recupera dentro de un horizonte pragmatista, viejos motivos de ascendencia kantiana y más allá platónica. Contra lo que podría suponerse a primera vista, por la vía del uso pragmático de la razón practica, el uso ético contextual vinculado a la aspiración a una vida buena, no ha suplantado las exigencias universalizantes del uso moral. Por el contrario, dentro de la actitud realizativa propia de los participantes en las interacciones morales, presuponemos la validez incondicionada de los convenios legítimos, que sirven de criterio contrafáctico para juzgar las prácticas efectivas. La aseverabilidad idealmente justificada en que consiste la validez moral (Habermas, 2002, $\S \S$ V y VI, pp. 283-293, p. 285), precisamente requiere que las pretensiones normativas en juego merezcan el reconocimiento proinclusión por parte de todos los excluidos.

En un arriesgado juego dirigido a verter en términos pragmáticos los postulados "trascendentes" de Kant, Habermas se atreve a establecer vía Pierce una analogía entre las kantianas “ideas de la razón” y los supuestos inmanentes de la ciencia y la moral humanas. En efecto, la suposición pragmática de un mundo objetivo común que sirve de referente compartido de los hablantes-actores, fue anticipado en la "Dialéctica trascendental" en la idea cosmológica de la unidad de mundo. La suposición pragmática de la racionalidad de actores responsables por las consecuencias de sus actos, remite al postulado de la libertad como condición de moralidad de los actos humanos. La trascendencia última propia del kantiano "ideal de la razón" como condición suprema última incondicionada de todas las condiciones, se actualiza pragmáticamente en la incondicionalidad (irrebasabilidad, diría Apel) de las pretensiones de validez comunicativas. Para terminar, el discurso racional como escenario último de toda posible justificación, remite a la razón como "facultad de los principios" erigida en tribunal supremo de los derechos y pretensiones del saber y de la acción. Desde luego, en los límites del pragmatismo, ya no se tratará de una razón a-temporal trascendente al mundo, 
sino de una razón detrascendentalizada que sólo actualiza las condiciones que constituyen inmanentemente los discursos teóricos y prácticos.

Por supuesto, no sería esta la oportunidad de evaluar esta lectura habermasiana de Kant, así que apuntemos provisionalmente que el riesgo que se corre en esta pragmatización de lo trascendental, radica en que la orientación de la carga se invierta, y se incurra en una nueva trascendentalización de lo pragmático. En lo personal, estimo que esta interpretación no le hace justicia a Habermas ni al propio Kant, pero debo reconocer que este tipo de analogías está en la base de quienes consideran los acuerdos racionales como imposiciones de una razón absoluta por encima de las contingencias históricas de la vida cotidiana. Por esa línea, se entiende equivocadamente que la pretensión habermasiana apunta a resolver la pluralidad de sentidos bajo la unidad de la razón comunicativa, cuando justamente se trata de lo contrario, disolver el imperio de una racionalidad ex-máquina en el fluir de las comunicaciones surgidas en los mundos de vida históricos.

Para terminar, retornemos a nuestros interrogantes iniciales. Si hemos asumido el nuevo escenario pragmatista de la ética discursiva, comprenderemos que la secuencia debe recorrerse en orden inverso al planteado allí. Son las luchas por ampliar la inclusión de los consensos morales las que fijan la justificación moral y desde allí la validez cognitiva de los enunciados prescriptivos. La opción por un cognitivismo analógico, obedece a que sólo así podemos dotar de objetividad dichas exigencias de reconocimiento, sin caer en un naturalismo reduccionista. Por el contrario, una posición relativista o escéptica, socava las exigencias valorativas inmanentes que efectivamente presuponemos en nuestras interacciones morales efectivas y en nuestras demandas de inclusión. En caso tal, la racionalidad comunicativa detrascenden- talizada, ahí sí se anularía en una "razón sin trascendencia", vale advertir, en una "razón intrascendente".

\section{Referencias}

Apel, K.O. (1967). El a priori de la comunidad de comunicación y los fundamentos de la ética. El problema de una fundamentación racional de la ética en la era de la ciencia. En Transformación de la filosofía (or. Transformation der Philosophie, 1973, trad. Adela Cortina, Joaquín Chamorro y Jesús Conill), (trad. 1984). Tomo II, (pp. 341- 413). Madrid: Taurus.

Apel, K.O. (1987). La ética del discurso como ética de la responsabilidad. Una transformación postmetafísica de la ética de Kant (trad. Norberto Smilg). En Teoría de la verdad yética del dicurso, (pp. 147-184). Barcelona: Paidós.

Boladeras, M. (1996). Comunicación, ética y política. Habermas y sus críticos. En Acción comunicativa y conciencia moral, (pp. 90-121). Madrid: Tecnos.

Cortina, A. (1989). La ética discursiva. En Camps, V. (edit.). Historia de la ética. Barcelona: Cátedra.

Cortina, A. \& Conill, J. (Coordinadores). (1999). Karl-Otto Apel: Una ética del discurso o dialógica. Revista Anthropos, 183, 111. Barcelona: Siglo del Hombre.

Cortina, A. (2000). Filosofía del diálogo en los umbrales del tercer milenio. En Muguerza, J. \& Cerezo, P. La filosofia hoy. (pp. 179- 187). Barcelona: Crítica.

Habermas, J. (1981). Teoría de la acción comunicativa, vol. I, (pp. 122 ss.). Madrid: Taurus. 
Habermas, J. (1989). Teorías de la verdad. En Teoría de la acción comunicativa. Complementos y estudios previos, (pp. 113-160). Madrid: Cátedra.

Habermas, J. (2000). Conciencia moral y acción comunicativa. En Conciencia moral y acción comunicativa. (Original alemán Moralbewusstein und Kommnunikatives Handeln, 1983, trad. Ramón García Cotarelo, 1985). (pp. 135- 219). Barcelona: Península.

Habermas, J. (2000). Ética del discurso. Notas sobre un programa de fundamentación. En Conciencia moral y acción comunicativa. (Original alemán Moralbewusstein und Kommnunikatives Handeln, 1983, trad. Ramón García Cotarelo, 1985). (pp. 57- 134). Barcelona: Península.

Habermas, J. (2000). Aclaraciones a la ética del discurso. (Original alemán Erläuterungen zur Diskursethik, 1991, trad. José Mardomingo). En Aclaraciones a la ética del discurso, (pp. 127-231). Madrid: Trotta.
Habermas, J. (2000). Del uso pragmático, ético y moral de la razón práctica. (Original alemán Zum pragmatischen, ethischen und moralischen Gebrauch der praktischen Vernunft, 1991, trad. José Mardomingo). En Aclaraciones a la ética del discurso, (pp. 109- 126). Madrid: Trotta.

Habermas, J. (2002). Verdad y justificación. (1999, trad. Pere Fabra y Luis Díez). Madrid: Trotta.

Habermas, J. (2002). Acción comunicativa y razón sin trascendencia. (Original alemán Kommunikatives Handeln und detranszendentalisierte Vernunft, trad. Pere Fabra). Barcelona: Paidós.

Sobrevilla, D. (1987). El programa de fundamentación de una ética discursiva de Jürgen Habermas. Ideas y Valores, 74-75, 99-117. Bogotá, Universidad Nacional.

Wellmer, A. (1994). Ética y diálogo. Elementos del juicio moral en Kant y en la ética del discurso. (Ethik und Dialog, 1986, trad. Fabio Morales). Barcelona: Anthropos- Universidad Autónoma Metropolitana. 